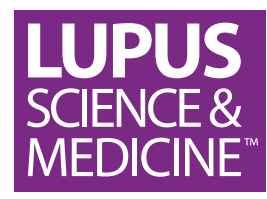

\title{
Clinical impact of hydroxychloroquine dose adjustment according to the American Academy of Ophthalmology guidelines in systemic lupus erythematosus
}

\author{
Ileana Vázquez-Otero, ${ }^{1}$ Nicolle Medina-Cintrón, ${ }^{1}$ Mariangelí Arroyo-Ávila, ${ }^{1}$ \\ Lorena González-Sepúlveda, ${ }^{2}$ Luis M Vilá (i) ${ }^{1}$
}

To cite: Vázquez-Otero I, Medina-Cintrón N, Arroyo-Ávila M, et al. Clinical impact of hydroxychloroquine dose adjustment according to the American Academy of Ophthalmology guidelines in systemic lupus erythematosus. Lupus Science \& Medicine 2020;7:e00395. doi:10.1136/ lupus-2020-000395

Received 13 March 2020 Revised 25 April 2020 Accepted 1 May 2020
Check for updates

(c) Author(s) (or their employer(s)) 2020. Re-use permitted under CC BY-NC. No commercial re-use. See rights and permissions. Published by BMJ.

'Division of Rheumatology, University of Puerto Rico Medical Sciences Campus, San Juan, Puerto Rico

${ }^{2}$ Puerto Rico Clinical and Translational Research Consortium, University of Puerto Rico Medical Sciences Campus, San Juan, Puerto Rico

Correspondence to Dr Luis M Vilá; luis.vila2@upr. edu

\section{ABSTRACT}

Objective The American Academy of Ophthalmology recommends a maximum hydroxychloroquine $(\mathrm{HCQ})$ dose of $\leq 5.0 \mathrm{mg} / \mathrm{kg} /$ day to reduce the risk of $\mathrm{HCQ}$-induced retinopathy. To determine if this dose adjustment would have an impact on the clinical course of SLE, we compared outcome measures in a cohort of patients with SLE before and after adjusting HCQ dose.

Methods Sixty Puerto Ricans with SLE (per 1997 American College of Rheumatology criteria) treated with $\mathrm{HCQ}$ who were changed to $\mathrm{HCQ} \leq 5.0 \mathrm{mg} / \mathrm{kg} /$ day were studied. Visits were ascertained every 6 months for 2 years before and 2 years after HCQ dose adjustment (baseline visit). Disease activity (per Systemic Lupus Erythematosus Disease Activity Index (SLEDAI)), SLE exacerbations, emergency room visits, hospitalisations, disease damage (per Systemic Lupus International Collaborating Clinics/American College of Rheumatology Damage Index), corticosteroids exposure, prednisone dose and immunosuppressive drugs exposure were determined before and after HCQ dose change.

Results At baseline visit, the mean age was $43.8 \pm 15.1$ years. All patients were women. The mean disease duration was $13.8 \pm 9.1$ years. After HCQ dose adjustment, patients required a lower prednisone dose when compared with visits before HCQ dose reduction. No significant differences were observed for mean SLEDAI scores, lupus exacerbations, emergency room visits, hospitalisations, disease damage and exposure to immunosuppressive drugs before and after HCQ dose adjustment.

Conclusions This study suggests that adjustment of daily $\mathrm{HCQ}$ dose to $\leq 5.0 \mathrm{mg} / \mathrm{kg} /$ day of actual body weight does not have a significant impact on the short-term and midterm outcomes in this group of patients with SLE.

\section{INTRODUCTION}

SLE is a chronic systemic autoimmune disorder characterised by a disruptive innate and adaptive immunity requiring immunomodulatory and immunosuppressive therapies. Hydroxychloroquine (HCQ), an antimalarial drug with immunomodulatory properties, remains one of the most important drugs in SLE. Multiple studies have demonstrated its favourable effects in SLE, such as reducing disease exacerbations, damage accrual and mortality. ${ }^{12}$ Despite its several therapeutic benefits, HCQ-induced retinal toxicity remains a major concern. This adverse event is reported to be below $1 \%$ during the first 5 years of drug treatment, but increases to $2 \%$ during the next 5 years and up to $20 \%$ after 20 years of therapy. ${ }^{3}$ For this reason, the American Academy of Ophthalmology (AAO) recommended guidelines regarding the screening and risks of retinal toxicity. Previously, the AAO recommended HCQ dose $\leq 6.5 \mathrm{mg} / \mathrm{kg} /$ day (ideal body weight) to reduce the risk of retinal toxicity, but in the revised guidelines of 2016 the safety dose was changed to $\leq 5 \mathrm{mg} / \mathrm{kg}$ /day (actual body weight). ${ }^{3}$ However, it is unclear if this change in HCQ dose has a significant impact on the short-term and long-term outcomes of patients with SLE and whether or not this dose reduction would be effective in controlling the disease. Therefore, we examined the effect of HCQ dose adjustment to $\leq 5 \mathrm{mg} / \mathrm{kg} /$ day on the clinical outcomes of a cohort of Puerto Ricans with SLE.

\section{METHODS}

\section{Study population}

A retrospective study was performed in a cohort of patients with SLE followed from July 1992 to March 2020 at the rheumatology clinic of the University of Puerto Rico Medical Sciences Campus and a private rheumatology practice located in San Juan, Puerto Rico. Patients with SLE whose HCQ dose was adjusted to $\leq 5 \mathrm{mg} / \mathrm{kg} /$ day of actual body 
weight were studied. All patients fulfilled the revised 1997 American College of Rheumatology (ACR) classification criteria for SLE, ${ }^{4}$ were $\geq 21$ years of age, had Puerto Rican ethnicity (self and four grandparents), received HCQ treatment (at stable dose) for at least 2 years prior to dose adjustment, and had 2 years of follow-up after dose adjustment. Those who developed HCQ-induced retinopathy and who discontinued HCQ were excluded. Baseline visit was defined as that where HCQ dose was adjusted to $\leq 5$ $\mathrm{mg} / \mathrm{kg} /$ day. HCQ dose adjustments were started in 2016 after publication of the AAO guidelines. Study visits were ascertained every 6 months for 2 years prior to and for 2 years after HCQ dose adjustment. A waiver for written informed consent was received.

\section{Baseline variables}

At baseline visit, information including demographic parameters (sex, age, SLE disease duration), cumulative (at any time until baseline visit) SLE manifestations (per ACR criteria), serological tests, disease activity, disease damage, selected comorbidities and pharmacological treatment was determined. Disease activity was assessed using the Systemic Lupus Erythematosus Disease Activity Index (SLEDAI) and disease damage by the Systemic Lupus International Collaborating Clinics/American College of Rheumatology Damage Index (SDI). ${ }^{56}$ Comorbidities included tobacco use, overweight/obesity (body mass index $\geq 25$ ), arterial hypertension, diabetes mellitus, dyslipidaemia, coronary artery disease, hypothyroidism, chronic kidney disease, cataracts and diabetic retinopathy. Current (within 1 month of baseline visit) and cumulative (at any time until baseline visit) SLE pharmacotherapy (corticosteroids, mycophenolate mofetil, azathioprine, cyclophosphamide, tacrolimus, methotrexate, rituximab and non-steroidal anti-inflammatory drugs) were gathered.

\section{Clinical outcomes}

Disease activity (per SLEDAI), SLE exacerbations, hospitalisations (any cause and hospitalisations attributed to SLE), emergency room visits (any cause and emergency room visits attributed to SLE), damage accrual (per SDI), prednisone (or equivalent) exposure and dose, and exposure to other immunosuppressive drugs were determined before and after baseline visits. SLE exacerbation was defined as an increase in disease activity requiring an adjustment of immunosuppressive therapy. ${ }^{7}$ Finally, mortality, if any, was assessed at these study periods.

\section{Patient and public involvement}

Patients or the public were not involved in the design, or conduct, or reporting, or dissemination plans of our research.

\section{Statistical analyses}

SLEDAI scores, SLE exacerbations, emergency room visits, hospitalisations, SDI score, prednisone (or equivalent) exposure, prednisone (or equivalent) mean dose and exposure to other immunosuppressive drugs were compared before and after HCQ dose adjustment. The mean number of exacerbations, emergency room visits and hospitalisations for each 6-month study period, before and after HCQ adjustment, was calculated. Visits before (24, 18, 12 and 6 months prior to baseline) and after (6, 12, 18 and 24 months after baseline) HCQ dose adjustment were grouped to make these comparisons. Furthermore, line graphs were used to display trends in prednisone dose, SLEDAI score and SDI score data. Statistical analyses were performed using exact McNemar's test and Wilcoxon signed-rank test, as appropriate. Statistical significance was set at $p<0.05$. Statistical analysis was performed using STATA V.15.

\section{RESULTS}

The entire cohort of patients with SLE consisted of 412 patients. Sixty (15\%) patients fulfilled the study criteria and were included in the analyses. The mean age (SD) of the study population was 43.8 (15.1) years, and all patients were women. The mean (SD) SLE duration was 13.8 (9.1) years and the mean (SD) HCQ treatment duration was 12.5 (15.1) years. At baseline, the mean (SD) height was $1.58(0.07) \mathrm{m}$ and weight was 58.4 (10.1) $\mathrm{kg}$. The mean (SD) HCQ doses before and after adjustment were 398.3 (12.8) mg/day and 246.7 (49.9) $\mathrm{mg}$ / day, respectively. The mean (SD) HCQ dose $/ \mathrm{kg}$ before and after adjustment were $6.8(1.2) \mathrm{mg} / \mathrm{kg}$ and $4.2(0.9)$ $\mathrm{mg} / \mathrm{kg}$, respectively. No deaths occurred during the study period. Table 1 shows the demographic characteristics, SLE manifestations, serological tests, SLEDAI score, SDI score, comorbid conditions and pharmacological therapy at baseline visit.

Table 2 depicts the outcome measures before and after HCQ dose adjustment. Patients required a lower mean prednisone (or equivalent) daily dose $(7.9 \pm 17.4 \mathrm{mg}$ vs $4.8 \pm 5.1 \mathrm{mg}, \mathrm{p}=0.047$ ) when compared with visits prior to HCQ dose reduction. No significant differences were observed regarding mean SLEDAI scores, lupus exacerbations, emergency room visits (any cause), emergency room visits attributed to SLE, mean hospitalisations (any cause), mean hospitalisations attributed to SLE and mean SDI before and after HCQ dose adjustment. Also, no differences were observed for exposure to corticosteroids, mycophenolate mofetil, azathioprine, cyclophosphamide, tacrolimus, rituximab or methotrexate. Furthermore, no significant differences were found for patients using prednisone higher than 5 and $7.5 \mathrm{mg}$ daily (at any moment) before and after HCQ dose change. Figure $1 \mathrm{~A}, \mathrm{~B}$ and $\mathrm{C}$ show the mean prednisone daily dose, SLEDAI scores and SDI scores, respectively, for each visit before and after HCQ dose adjustment. Compared with baseline visit, no significant differences were observed for SLEDAI scores or SDI scores for each study visit before and after HCQ change.

We further stratified patients according to HCQ dose adjustment. Thirty-one patients had a dose reduction of $200 \mathrm{mg}$ daily and 29 patients had a dose reduction of 
Table 1 Baseline demographic characteristics, SLE manifestations, serological tests, disease activity, disease damage, comorbid conditions and pharmacological therapy

\section{Characteristics}

\begin{tabular}{ll}
\hline Sex, \% female & 100 \\
Age, mean (SD) & $43.8(15.1)$ \\
SLE duration, mean years (SD) & $13.8(9.1)$
\end{tabular}

Cumulative ACR criteria, \%

\begin{tabular}{|rr}
\hline Malar rash & 51.7 \\
\hline Discoid rash & 8.3 \\
\hline Photosensitivity & 61.7 \\
\hline Oral ulcers & 35.0 \\
\hline Non-scarring alopecia & 28.8 \\
\hline Arthritis & 80.0 \\
\hline Pericarditis & 11.7 \\
\hline Pleuritis & 13.3 \\
\hline Cellular casts & 16.7 \\
\hline Proteinuria & 40.0 \\
\hline Seizures & 10.0 \\
\hline Psychosis & 3.3 \\
\hline Haemolytic anaemia & 3.3 \\
\hline Leucopenia $\left(<4.0 \times 10^{9} / L\right)$ & 61.7 \\
\hline Lymphopaenia $\left(<1.5 \times 10^{9} /\right.$ L) & 86.7 \\
\hline Thrombocytopaenia $(<100 \times$ & 8.3 \\
\hline 10 $/$ L) & \\
\hline ANA & 95.0 \\
\hline Anti-dsDNA antibodies & 71.7 \\
\hline Anti-Smith antibodies & 20.0 \\
\hline Anticardiolipin antibodies & 23.3 \\
\hline Lupus anticoagulant test & 13.3 \\
\hline
\end{tabular}

Other serological tests, \%

\begin{tabular}{|c|c|}
\hline Anti-Ro antibodies & 33.3 \\
\hline Anti-La antibodies & 11.7 \\
\hline Low C3 & 72.9 \\
\hline Low C4 & 66.1 \\
\hline \multicolumn{2}{|l|}{ SLEDAI } \\
\hline Mean score (SD) & $1.75(3.1)$ \\
\hline Median score (P25-P75) & $0(0-2)$ \\
\hline \multicolumn{2}{|l|}{ SDI } \\
\hline Mean score (SD) & $0.91(1.4)$ \\
\hline Median score (P25-P75) & $0(0-1.5)$ \\
\hline \multicolumn{2}{|l|}{ Comorbidities, \% } \\
\hline Tobacco use & 6.7 \\
\hline Overweight/obesity & 20.0 \\
\hline Arterial hypertension & 50.0 \\
\hline Diabetes mellitus & 3.3 \\
\hline Dyslipidaemia & 41.7 \\
\hline
\end{tabular}

Continued

\begin{tabular}{lcc}
\hline Table 1 Continued & \\
\hline Characteristics & & \\
\hline Coronary artery disease & 1.7 & \\
\hline Hypothyroidism & 20.0 & \\
Chronic kidney disease & 3.3 & \\
\hline Cataracts & 11.7 & \\
\hline Diabetic retinopathy & 0.0 & \\
SLE treatment, \% & Current & Cumulative \\
\hline Corticosteroids & 56.7 & 98.3 \\
\hline Mycophenolate mofetil & 28.3 & 38.3 \\
\hline Azathioprine & 5.1 & 33.3 \\
\hline Cyclophosphamide & 0.0 & 20.0 \\
\hline Tacrolimus & 3.3 & 6.7 \\
\hline Methotrexate & 1.7 & 11.7 \\
\hline Rituximab & 0.0 & 3.3 \\
\hline NSAIDs & 10.2 & 50.0 \\
\hline ACR,Ameican Colege Rhentolog:Ant-d DA
\end{tabular}

ACR, American College of Rheumatology; Anti-dsDNA, anti-double stranded DNA; NSAIDs, non-steroidal anti-inflammatory drugs; P, percentile; SDI, Systemic Lupus International Collaborating Clinics/ American College of Rheumatology Damage Index; SLEDAI, Systemic Lupus Erythematosus Disease Activity Index.

$100 \mathrm{mg}$ daily. For each group of patients, no differences were observed before and after HCQ dose adjustments with regard to SLEDAI scores, lupus exacerbations, emergency room visits, hospitalisations, SDI scores and exposure to immunosuppressive drugs (data not shown).

\section{DISCUSSION}

We examined the clinical outcomes in a group of patients with SLE from Puerto Rico whose HCQ dose was decreased to $\leq 5 \mathrm{mg} / \mathrm{kg}$ / day (actual body weight) according to the 2016 AAO guidelines regarding HCQ-induced retinopathy. We did not observe significant differences in disease activity, SLE exacerbations, emergency room visits, hospitalisations, damage accrual, and exposure to corticosteroids or other immunosuppressive therapies before and 2 years after HCQ dose change. The mean prednisone daily dose was lower after HCQ dose adjustment. Thus, our findings suggest that adjusting HCQ dose per the AAO recommendations does not have a significant impact on the clinical outcomes of patients with SLE.

Few data exist regarding the therapeutic concentrations at which HCQ exerts its immunomodulatory properties at the cellular level. The effect of HCQ dosing in the modulation of inflammatory cytokines has not been extensively studied. HCQ exerts its immunomodulatory effect by downregulating Toll-like receptors (TLRs) 3, 7 and 9 in plasmacytoid dendritic cells. These are the major producers of interferon- $\alpha$ (IFN- $\alpha$ ), which is known to have a major role in the pathogenesis of SLE. ${ }^{8}$ In a group of patients with SLE from LUMINA, Willis $e t$ a $l^{8}$ found that treatment with $\mathrm{HCQ}$ was associated with reduced levels of tumour necrosis factor- $\alpha(\mathrm{TNF}-\alpha)$ and IFN- $\alpha$ 
Table 2 Clinical outcomes and pharmacological therapy before and after HCQ dose adjustment

\begin{tabular}{|c|c|c|c|}
\hline Parameters & $\begin{array}{l}\text { Visits prior to } \\
\text { adjustment }\end{array}$ & Visits after adjustment & $P$ value \\
\hline \multicolumn{4}{|l|}{ Outcome measures } \\
\hline \multicolumn{4}{|l|}{ SLEDAI } \\
\hline Mean score (SD) & $2.2(2.9)$ & $2.1(3.0)$ & 0.958 \\
\hline Median score (P25-P75) & $1(0-3)$ & $1(0-3.1)$ & \\
\hline \multicolumn{4}{|l|}{ SLE exacerbations } \\
\hline Mean (SD) & $0.18(0.25)$ & $0.13(0.21)$ & 0.256 \\
\hline Median (P25-P75) & $0(0-0.25)$ & $0(0-0.25)$ & \\
\hline \multicolumn{4}{|l|}{ Total emergency room visits, mean (SD) } \\
\hline Mean $(\mathrm{SD})$ & $0.06(0.22)$ & $0.01(0.05)$ & 0.284 \\
\hline Median (P25-P75) & $0(0-0)$ & $0(0-0)$ & \\
\hline \multicolumn{4}{|l|}{ Emergency room visits attributed to SLE } \\
\hline Mean (SD) & $0.02(0.08)$ & $0.00(0.03)$ & 0.313 \\
\hline Median (P25-P75) & $0(0-0)$ & $0(0-0)$ & \\
\hline \multicolumn{4}{|l|}{ Total hospitalisations } \\
\hline Mean (SD) & $0.08(0.19)$ & $0.04(0.10)$ & 0.322 \\
\hline Median (P25-P75) & $0(0-0)$ & $0(0-0)$ & \\
\hline \multicolumn{4}{|l|}{ Hospitalisations attributed to SLE } \\
\hline Mean (SD) & $0.04(0.16)$ & $0.00(0.03)$ & 0.083 \\
\hline Median (P25-P75) & $0(0-0)$ & $0(0-0)$ & \\
\hline \multicolumn{4}{|l|}{ SDI } \\
\hline Mean score (SD) & $0.84(1.28)$ & $0.98(1.42)$ & 0.076 \\
\hline Median score (P25-P75) & $0(0-1)$ & $0(0-1.5)$ & \\
\hline \multicolumn{4}{|l|}{ Pharmacological therapy } \\
\hline Corticosteroids, \% & 68.3 & 65.0 & 0.727 \\
\hline \multicolumn{4}{|l|}{ Prednisone (or equivalent) } \\
\hline Mean mg/day (SD) & $7.9(17.4)$ & $4.8(5.1)$ & 0.047 \\
\hline Median mg/day (P25-P75) & $5(0-9.8)$ & $5(0-7.7)$ & \\
\hline Prednisone $>5 \mathrm{mg}$ daily at any point, $\%$ & 48.3 & 40.0 & 0.230 \\
\hline Prednisone $>7.5 \mathrm{mg}$ daily at any point, $\%$ & 45.0 & 35.0 & 0.150 \\
\hline Mycophenolate, \% & 28.3 & 30.0 & $>0.99$ \\
\hline Azathioprine, \% & 10.0 & 8.3 & $>0.99$ \\
\hline Cyclophosphamide, \% & 1.7 & 1.7 & $>0.99$ \\
\hline Tacrolimus, \% & 1.7 & 6.7 & 0.250 \\
\hline Methotrexate, \% & 3.3 & 5.0 & $>0.99$ \\
\hline Rituximab, \% & 0.0 & 0.0 & $>0.99$ \\
\hline NSAIDs, \% & 15.0 & 18.3 & 0.688 \\
\hline
\end{tabular}

Exact McNemar's test or Wilcoxon signed-rank test was used for statistical analyses.

$\mathrm{HCQ}$, hydroxychloroquine; NSAIDs, non-steroidal anti-inflammatory drugs; P, percentile; SDI, Systemic Lupus International Collaborating Clinics/American College of Rheumatology Damage Index; SLEDAI, Systemic Lupus Erythematosus Disease Activity Index.

compared with patients with SLE not receiving HCQ, and that the reduction in IFN- $\alpha$ levels strongly correlated with lower disease activity. Noteworthy, Sacre $e t a t^{\theta}$ found no significant differences in IFN- $\alpha$ and TNF- $\alpha$ production by plasmacytoid dendritic cells on in vitro stimulation of TLR-7 and TLR-9 between subjects receiving $400 \mathrm{mg}$ / daily and $200 \mathrm{mg}$ /daily of HCQ. These findings suggest that proinflammatory cytokine inhibition by HCQ may be achieved with lower doses of the drug.

HCQ has a distinctive pharmacokinetic profile. Its bioavailability has been reported to be approximately $70 \%$ with an extensive tissue distribution. HCQ has a long elimination half-life of nearly 40 days and steadystate levels are achieved after 6 months of therapy. ${ }^{10}$ As 

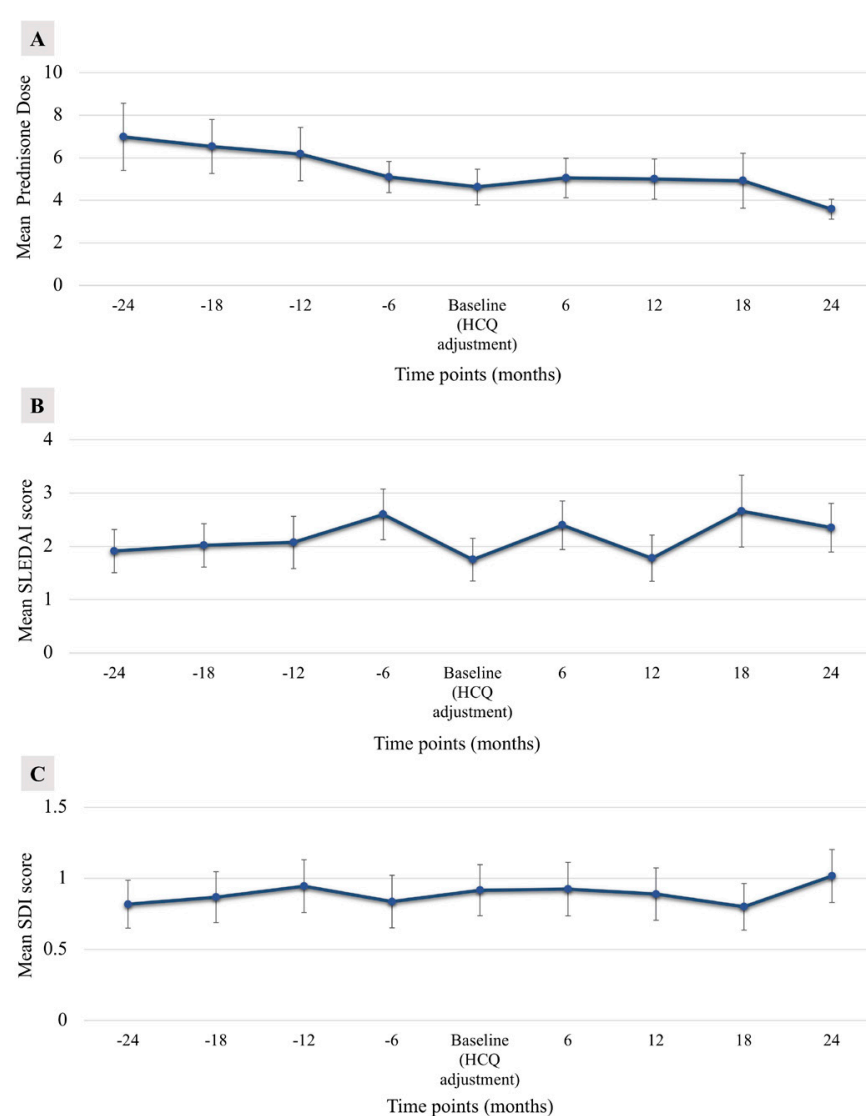

Figure 1 Means $( \pm S E)$ of $(A)$ prednisone dose (mg/day), (B) Systemic Lupus Erythematosus Disease Activity Index (SLEDAl) scores and (C) Systemic Lupus International Collaborating Clinics/American College of Rheumatology Damage Index (SDI) scores for each study visit before and after HCQ dose adjustment are shown. HCQ, hydroxychloroquine.

a result, the relationship between dosing, therapeutic blood concentration and its correlation with SLE disease activity remains uncertain. Durcan et $a l^{11}$ observed an association between lower HCQ blood concentrations and higher disease activity in patients with SLE. Likewise, Costedoat-Chalumeau et $a l^{12}$ found that low HCQ concentration was a predictor of SLE exacerbations and higher disease activity, and proposed a therapeutic level whole blood concentration of $1000 \mathrm{ng} / \mathrm{mL}$. However, in the PLUS study the same authors found that adapting HCQ dose to achieve HCQ concentration levels $>1000 \mathrm{ng} /$ $\mathrm{mL}$ did not reduce SLE flares over a 7-month follow-up period. ${ }^{13}$

Few studies have examined the clinical effect of lowering HCQ dose in patients with SLE. Grossman $e t a l^{14}$ studied a population of patients with SLE who received different body weight-based doses of $<4 \mathrm{mg} / \mathrm{kg} /$ day, $4-4.99 \mathrm{mg} /$ $\mathrm{kg} /$ day, $5-5.99 \mathrm{mg} / \mathrm{kg} /$ day and $\geq 6 \mathrm{mg} / \mathrm{kg} /$ day and found no differences in disease activity among the different dosing groups. They also noted no differences in disease exacerbations using the Safety of Estrogens in Lupus Erythematosus National Assessment (SELENA)-SLEDAI flare instrument and no significant changes in patients' global assessment. ${ }^{14}$ These findings are in line with those reported in our study.

Some limitations of our study must be highlighted. First, the study population was small. Also, we did not make comparisons with patients who did not require HCQ adjustment, particularly with those who were near the cut-off as the latter group of patients was very small. Nonetheless, we considered the natural course of SLE characterised by fluctuations in disease expression and analysed trends in outcome variables for 2 years before HCQ adjustment; thus, we could better compare with the disease course after dose adjustment. Second, this study was performed in a group of Puerto Rican patients who may not be representative of other ethnic groups. Third, no male patients were included as none of those participating in the entire cohort required dose adjustment. Fourth, we did not gather data concerning adherence to immunosuppressive drugs, including HCQ. Nevertheless, adequate adherence may be inferred by the low levels of SLE disease activity observed in our study population, both before and after HCQ dose adjustment. Finally, the follow-up period of 2 years was relatively short to determine the impact of HCQ dose adjustment on the longterm outcomes. The Canadian Hydroxychloroquine Study Group studied the long-term effect of HCQ withdrawal in patients with SLE with stable disease and found that during 3 years of follow-up 50\% of patients who discontinued HCQ experienced a major flare of their disease compared with $28 \%$ of those who continued treatment. ${ }^{15}$ The mean time to major SLE exacerbation was 29.4 months after drug withdrawal. This study suggests that the protective effects of HCQ remain for a long period of time, possibly longer if the drug dose is lowered rather than discontinued such as in our research work.

In conclusion, this study suggests that the adjustment of HCQ daily dose to $\leq 5 \mathrm{mg} / \mathrm{kg} /$ day of actual body weight does not have a significant impact on the short-term and mid-term outcomes of patients with SLE. Nevertheless, further studies including a larger number of patients and longer follow-up are necessary to reach further conclusions.

Contributors All authors participated sufficiently in this work to take responsibility for the work and to qualify as authors as defined in the Uniform Requirements for Manuscripts Submitted to Biomedical Journals. All authors were involved in drafting the article or revising it critically for important intellectual content, and all approved the final version to be published.

Funding This study was funded by the National Institute on Minority Health and Health Disparities (NIMHD) and the National Institute of Allergy and Infectious Diseases (NIAID) of the National Institute of Health (grant number U54MD007587).

Competing interests None declared.

Patient consent for publication Not required.

Ethics approval Ethical approval for this study was obtained from the University of Puerto Rico Medical Sciences Campus Institutional Review Board (approval number: A6310119). All procedures followed were in accordance with the Declaration of Helsinki.

Provenance and peer review Not commissioned; externally peer reviewed. Data availability statement All data relevant to the study are included in the article or uploaded as supplementary information. 
Open access This is an open access article distributed in accordance with the Creative Commons Attribution Non Commercial (CC BY-NC 4.0) license, which permits others to distribute, remix, adapt, build upon this work non-commercially, and license their derivative works on different terms, provided the original work is properly cited, appropriate credit is given, any changes made indicated, and the use is non-commercial. See: http://creativecommons.org/licenses/by-nc/4.0/.

ORCID iD

Luis M Vilá http://orcid.org/0000-0002-6679-2704

\section{REFERENCES}

1 Fessler BJ, Alarcón GS, McGwin G, et al. Systemic lupus erythematosus in three ethnic groups: XVI. Association of hydroxychloroquine use with reduced risk of damage accrual. Arthritis Rheum 2005;52:1473-80.

2 Alarcón GS, McGwin G, Bertoli AM, et al. Effect of hydroxychloroquine on the survival of patients with systemic lupus erythematosus: data from LUMINA, a multiethnic US cohort (LUMINA L). Ann Rheum Dis 2007;66:1168-72.

3 Marmor MF, Kellner U, Lai TYY, et al. Recommendations on screening for chloroquine and hydroxychloroquine retinopathy (2016 revision). Ophthalmology 2016;123:1386-94.

4 Hochberg MC. Updating the American College of rheumatology revised criteria for the classification of systemic lupus erythematosus. Arthritis Rheum 1997;40:40:1725.

5 Mikdashi J, Nived O. Measuring disease activity in adults with systemic lupus erythematosus: the challenges of administrative burden and responsiveness to patient concerns in clinical research. Arthritis Res Ther 2015;17:183.

6 Gladman DD, Goldsmith $\mathrm{CH}$, Urowitz MB, et al. The systemic lupus international collaborating Clinics/American College of rheumatology
(SLICC/ACR) damage index for systemic lupus erythematosus international comparison. J Rheumatol 2000;27:373-6.

7 Petri M, Buyon J, Kim M. Classification and definition of major flares in SLE clinical trials. Lupus 1999;8:685-91.

8 Willis R, Seif AM, McGwin G, et al. Effect of hydroxychloroquine treatment on pro-inflammatory cytokines and disease activity in SLE patients: data from LUMINA (LXXV), a multiethnic US cohort. Lupus 2012;21:830-5.

9 Sacre K, Criswell LA, McCune JM. Hydroxychloroquine is associated with impaired interferon-alpha and tumor necrosis factor-alpha production by plasmacytoid dendritic cells in systemic lupus erythematosus. Arthritis Res Ther 2012;14:R155.

10 Tett SE, Cutler DJ, Day RO, et al. A dose-ranging study of the pharmacokinetics of hydroxy-chloroquine following intravenous administration to healthy volunteers. Br J Clin Pharmacol 1988;26:303-13.

11 Durcan L, Clarke WA, Magder LS, et al. Hydroxychloroquine blood levels in systemic lupus erythematosus: clarifying dosing controversies and improving adherence. J Rheumatol 2015;42:2092-7.

12 Costedoat-Chalumeau N, Amoura Z, Hulot J-S, et al. Low blood concentration of hydroxychloroquine is a marker for and predictor of disease exacerbations in patients with systemic lupus erythematosus. Arthritis Rheum 2006;54:3284-90.

13 Costedoat-Chalumeau N, Galicier L, Aumaître O, et al. Hydroxychloroquine in systemic lupus erythematosus: results of a French multicentre controlled trial (plus study). Ann Rheum Dis 2013;72:1786-92.

14 Grossman JM, Clowse MEB, Izmirly PM, et al. Hydroxychloroquine dosing and disease activity in a large multi-racial lupus cohort. Arthritis and Rheumatology 2014;66.

15 Tsakonas E, Joseph L, Esdaile JM, et al. A long-term study of hydroxychloroquine withdrawal on exacerbations in systemic lupus erythematosus. The Canadian hydroxychloroquine Study Group. Lupus 1998;7:80-5. 